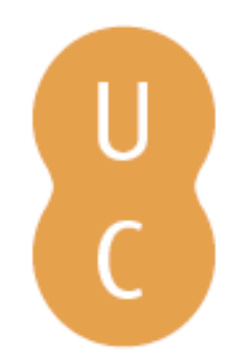

\title{
nombalina
}

\section{A criança e a pedologia no contexto da Primeira República em Portugal}

\author{
Autor(es): $\quad$ Ferreira, António Gomes
}

Publicado por: Imprensa da Universidade de Coimbra

URL

persistente: $\quad$ URI:http://hdl.handle.net/10316.2/35879

DOI: $\quad$ DOI:http://dx.doi.org/10.14195/978-989-26-0862-4_12

Accessed : $\quad$ 26-Apr-2023 03:57:11

A navegação consulta e descarregamento dos títulos inseridos nas Bibliotecas Digitais UC Digitalis, UC Pombalina e UC Impactum, pressupõem a aceitação plena e sem reservas dos Termos e Condições de Uso destas Bibliotecas Digitais, disponíveis em https://digitalis.uc.pt/pt-pt/termos.

Conforme exposto nos referidos Termos e Condições de Uso, o descarregamento de títulos de acesso restrito requer uma licença válida de autorização devendo o utilizador aceder ao(s) documento(s) a partir de um endereço de IP da instituição detentora da supramencionada licença.

Ao utilizador é apenas permitido o descarregamento para uso pessoal, pelo que o emprego do(s) título(s) descarregado(s) para outro fim, designadamente comercial, carece de autorização do respetivo autor ou editor da obra.

Na medida em que todas as obras da UC Digitalis se encontram protegidas pelo Código do Direito de Autor e Direitos Conexos e demais legislação aplicável, toda a cópia, parcial ou total, deste documento, nos casos em que é legalmente admitida, deverá conter ou fazer-se acompanhar por este aviso.

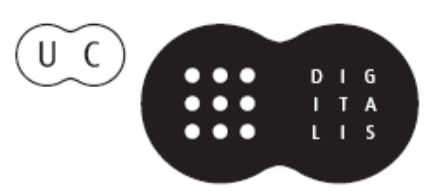




\title{
A EXPERIÊNCIA DA PRIMEIRA REPÚBLICA NO BRASIL E EM PORTUGAL
}

\author{
ALDA MOURÃO \\ ANGELA DE CASTRO GOMES
}

COORDENAÇÃO 


\section{A criança e a pedologia no contexto da Primeira República em Portugal}

António Gomes Ferreira

A criança é fundamentalmente um ser humano em via de crescimento; é um homem ou uma mulher em via de formação. A sua principal função é crescer, procurando atingir a grandeza que a hereditariedade lhe destinou e alcançar o equilíbrio morfológico e fisiológico do adulto, que constitui a perfeição do ser. Respeitar o crescimento, a lei natural do crescimento, é o principal dever do educador, e tôda a educação se tem de subordinar a esta questão de medida: não perturbar a lei natural do crescimento (Ferreira, 1920:30).

NÁO RARAS VEZES CAÍMOS NUMA RACIONALIDADE DE MODERNIDADE, COMO se o moderno traduzisse uma verdade intuída instantaneamente, esquecendo-se muitas vezes que o processo que a sustentou chega a ser mais elucidativo que a expressão que a consagra. A modernidade está associada à confiança na razão e na capacidade de o ser humano entender e agir sobre o meio em que atua, o que significou a valorização do investimento e a admissão da mudança. Não será impertinente buscar as origens da modernidade nas novidades do Renascimento e nas descobertas dos navegadores de Quatrocentos e Quinhentos, onde os portugueses deixaram grande marca. Não terá sido esta experiência que permitiu a Luís de Camóes escrever: "Mudam-se os tempos, mudam-se as vontades,/ Muda-se o ser, muda-se a confiança;/ Todo o Mundo é composto de mudança,/ Tomando sempre 
novas qualidades"? Diante de tanta mudança sentida, já seria necessário algo maior para que causasse espanto a mudança, pois que como escrevia o grande poeta: "Que não se muda já como soía”. Mas a mudança inerente ao arranque da modernidade é, sobretudo, psicológica, atitudinal, intelectual. Ela caracteriza-se pelo desligar da cosmovisáo finalista do mundo, própria do período anterior, e pela adoção de uma concepção aberta ao exercício da razão, da observação e da experimentação, que arrancará claramente a partir de Seiscentos, ganhando força nos séculos seguintes, mas não sem que tenha merecido contestaçáo, nuns períodos mais evidente do que noutros, até ao século XX.

Em conexão com esta postura, a ordem aristocrática vai cedendo espaço ao crescendo de importância da burguesia e à afirmação dum poder público que, cada vez mais, vai buscar legitimidade na capacidade de garantir maior igualdade de direitos e de captação dos entấo capazes de assegurar o sucesso da instituição e do país. É este desalinhar com a ortodoxia ideológica demasiado dependente do poder coativo da Igreja e da rigidez da lógica aristocrática que pode justificar a compreensão da "descontinuidade" de Giddens (1995). Para este autor, tal "descontinuidade" evidencia-se, desde logo, no aumento do ritmo das mudanças, que, sendo mais notório no domínio da tecnologia, não deixa de contemplar outras áreas no processo de mudança, implicando inclusive a emergência de novas formas de produção e de organização da sociedade e de poder. Na medida em que o saber é avaliado pelo seu impacto no sucesso da atividade, ele tende a constituir-se um fator de mudança e uma característica da modernidade. Assim percebido leva a que a família e as instituiçóes públicas se interessem pelo processo que devia garantir maior acesso aos conhecimentos instrumentais, condição fundamental para alargar a base de recrutamento de recursos humanos e suportar uma ordem política que se legitimava na escolha do povo. É por isso que a escola se generaliza e se tornou estratégica para os governos contemporâneos. Na verdade, "ela mostrou-se mais adequada que qualquer outra instituição às exigências de formação requeridas por uma sociedade cada vez mais marcada por uma dinâmica económica capitalista e/ou por uma burocracia administrativa cada vez mais controladora e sofisticada" (Ferreira, 2005). A escola, tanto pela sua organizaçáo quanto pelos conteúdos e também pela populaçáo que foi abrangendo, foi-se mostrando uma 
instituição moldável ao processo de modernização da sociedade. Essa característica torna-a apetecível e suscetível de facilmente ser utilizada pelo poder.

A instauração da República em Portugal, em 1910, traduz uma clara vontade de colocar o país no caminho do futuro. De facto, o novo regime promoveu um frenético desejo de mudança e os seus protagonistas pensaram que o futuro da sociedade dependia da educação. A educação era a "pedra de toque" do desenvolvimento. $\mathrm{O}$ decreto que instituía a reforma do ensino primário não podia ser mais enfático nessa associação, dizendo no seu preâmbulo: "E só se pode fazer progredir e desenvolver uma sociedade, fazendo com que a acção continua, incessante e persistente de educação, attinja o ser humano, sob o tríplice aspecto: phisico, intellectual e moral" (dec. 29 de Março de 1911). Mas a verdadeira transformação só aconteceria a partir da educação das crianças que seguisse uma concepçáo positivista, uma educaçáo que integrasse a criança na natureza "não para ficar abandonada às suas forças tempestuosas, mas para as aproveitar no fim supremo de dar a si própria unidade moral e aos seus semelhantes solidariedade affectiva”. O tom geral do decreto traduz claramente a pretendida mudança de verdade. A criança passava agora a deixar de estar submetida à influência da religião católica para iniciar um processo de emancipação dos falsos dogmas, adotando uma moral utilitária de solidariedade e uma instrução prática e intuitiva. Pelo menos era o que se devia passar entre os republicanos e no campo escolar. De acordo com o referido decreto (de 29 de Março de 1911), a "moral das escolas depois que a Republica se fundou, só tem por base os preceitos que regulam a justiça entre homens e a dignidade dos cidadãos".

É inegável que a modernidade da moral e da educação republicana em Portugal se filiava no movimento da ilustração setecentista e principalmente nos legados de Kant e Condorcet e do naturalismo iniciado por Jean-Jacques Rousseau. No que diz respeito à origem da moral, Rousseau era bem claro, ao dizer que se limitava a seguir apenas a religião natural. Interrogava-se ele:

Que pureza de moral, que dogma útil para o homem e honroso para o seu autor poderei retirar de uma doutrina passiva, que não possa retirar do bom uso das minhas faculdades, sem necessidade daquela? Mostrai-me o que se pode acrescentar — para a glória de Deus, para o bem da sociedade e para meu próprio bem - aos deveres da lei natural, e a que virtude dareis origem com um novo culto, 
que náo seja uma consequência do meu. As maiores ideias sobre a Divindade chegam-nos unicamente através da razáo. Vede o espectáculo que a natureza nos oferece, escutai a voz interior" (Rousseau, 1990:106).

Para Rousseau, a natureza é a grande fonte de conhecimento e a grande referência pedagógica. Dela advém a orientaçáo que deve seguir-se na educaçáo da pessoa como a realidade que é preciso compreender e respeitar. No fundo, ele advoga uma aprendizagem interacionista, e, durante a infância, o estudo devia ser feito nas relaçôes com as coisas e posteriormente, quando o indivíduo começava "a sentir o seu ser moral”, devia avançar nos seus estudos "através das suas relações com os homens" (Rousseau, 1990:10).

É a valorização da liberdade da pessoa que também está no centro do pensamento de Kant. Para este filósofo, o homem pode seguir os seus impulsos ou a razão, mas para ser moral tem de obedecer a um imperativo categórico. Um indivíduo educado é aquele que pela razão se afasta da barbárie, aquele que procura tornar-se melhor, educando-se a si mesmo com base em princípios.

Mas é em Condorcet que podemos encontrar mais as ideias que os republicanos enfatizaram. Também ele quer que o homem se torne no sujeito da sua própria educação e, por isso, ele vai ser um dos pioneiros a advogar uma generalização da instrução e a defender uma escola pública que permitisse às pessoas libertar-se da dependência intelectual. Ele vai mais longe e desenvolve uma argumentação que terá muito uso nos séculos posteriores: o conhecimento e a verdade são a base de uma formação necessária a uma sociedade próspera e sustentada.

Para Condorcet, a formação intelectual de aquisição de informação é tão relevante quanto ele considera que a desigualdade de instrução é uma espécie de tirania. Muitos dos liberais e, depois, dos republicanos tenderão a assumir idêntica posição, embora no século XX ela já apareça atenuada por uma concepção pedagógica influenciada pela ideia de desenvolvimento do indivíduo muito inspirada em Rousseau. Isso significa uma maior preocupação com a adequação dos conteúdos e dos processos do ensino à idade da criança. Embora tal preocupação não constituísse novidade no campo do pensamento pedagógico, ela aparecia agora mais disseminada e mais sustentada em tentativas de legitimação científica. Outra ideia forte que prevalece neste período das últimas décadas do século XIX e as três primeiras do seguinte é a de edu- 
cação integral, ideia que emerge nos primórdios da modernidade e projeta, sobretudo, a partir de Locke uma ambição pedagógica de formação do indivíduo que devia assegurar uma população melhor preparada para responder às necessidades de economias mais exigentes e de Estados melhor organizados. Tudo isto está em jogo e, parecendo, por vezes, paradoxal, acaba por desaguar numa visão pedagógica que coloca a criança no centro do processo das políticas de desenvolvimento dos países mais confrontados com a lógica da modernizaçáo. No início do século XX, Faria de Vasconcellos traduzia muito bem essa concepção pedocêntrica que vinha de Rousseau, ao escrever:

Ora a creança constitue, tanto physica como psychicamente um typo especial que difere não só quantitativamente mas qualitativamente do adulto. D'onde a necessidade de tratar a creança como uma creança, de náo perturbar e contrariar a natureza, de conformar o ensino e a educaçáo ao seu estado de desenvolvimento physico e psychico e de recorrer portanto a meios que a creança sinta e compreenda (Faria de Vasconcellos, s.d.:7-8).

Esta ideia pulula já por entre a intelectualidade mais progressista e atenta às transformações das sociedades na transição do século XIX para o XX. Mas ela é tanto resultado duma sensibilidade inserida num contexto cultural romântico como das grandes transformaçôes ideológicas, sociais e científicas. $\mathrm{O}$ desenvolvimento da ciência, a emergência de novas realidades económicas, a visibilidade dos problemas sociais provocados pela industrialização, a necessidade de aumentar a qualidade sanitária da população fizeram com que vários intelectuais, pedagogos, moralistas, políticos se interessassem pelas condiçóes de criação e educação das crianças. Esta atençáo sobre a criança encontrou especial acolhimento entre a classe médica que, ao longo de Oitocentos, procurará abarcar um amplo campo de intervenção que se estenderá desde os cuidados individuais até às condiçôes sanitárias das crianças menos favorecidas e aos novos espaços frequentados pelos mais pequenos. Em face da emergente escolarização, médicos inseridos no movimento higienista, muito em sintonia com o alinhamento intelectual positivista, vão pretender delinear uma abordagem pedagógica que se pretende fundada na fisiologia e na busca da medida adequada ao desenvolvimento da criança (Ferreira, 2010). Sente-se a vontade de constituir-se um saber pedagógico articulado com a tecnologia médica e 
com ele desenvolver uma atuação educativa científica, nomeadamente na escola. Acresce, por outro lado, que a nova sensibilidade filantrópica, aliada às preocupaçôes educacionais resultantes das dinâmicas sociais, culturais e políticas do século XIX, propicia o surgimento de um movimento pedagógico que procura fomentar instituiçóes para crianças que ainda não estão em idade de frequentar a escola primária, mas onde se devia promover uma educaçáo que tivesse um claro propósito de atender ao desenvolvimento sensorial, intelectual e social dos que as frequentassem (Ferreira, 2010). Este contexto social, cultural e científico proporcionava condiçóes muito favoráveis ao desenvolvimento de um pensamento pedagógico que requeria um estudo mais profundo sobre a criança.

Convém também recordarmos que a segunda metade de Oitocentos vê crescer uma corrente de pensamento cientificista que tem grandes consequências no modo como se busca compreender o ser humano bem como as formas como vive e se organiza. O interesse pela criança não está, por isso, desligado da tentativa de se compreender o ser humano e o indivíduo adulto. Mais que o reflexo de uma vontade individual, deve-se enquadrar a dinâmica da emergência de uma ciência da criança e do emergir da psicologia genética como uma conjugação de circunstâncias em que o processo de desenvolvimento científico se articulou com a disposição sociocultural então existente. Acreditando-se que era possível atuar sobre a transformaçáo do indivíduo, tornava-se necessário compreender como ele se desenvolvia.

$\mathrm{O}$ investimento no estudo da criança não era um mero exercício de filantropismo. Não era, seguramente, tão só a ternura da infância ou o ideal romântico da ingénua bondade da criança que motivara alguns dos autores a investir na compreensão psicológica dos mais pequenos. Mas sendo da natureza da psicologia a compreensão da pessoa, ela partilhava do interesse que a criança vinha suscitando social e cientificamente. Baldwin escreveu, no seu livro intitulado Desenvolvimento mental na criança e na espécie (1895), que a amplitude da concepção da psicologia estava certamente de acordo com as concepçóes de há muito aceites em outros ramos da pesquisa científica, mas que uma fase dessa ampliação da pesquisa psicológica só se tornava notória quando interpretada à luz da doutrina da evoluçáo. De facto, Baldwin acentuava bem que o estudo das crianças era o único meio de verificar as análises mentais do adulto, já que, no seu entender, só através do estudo do desenvolvimento in- 
telectual na infância se podia chegar à compreensão da génese dos factos complexos. Segundo este autor, a psicologia genética, além de fornecer análises definitivas de numerosos estados mentais que não se mostravam acessíveis, tinha a vantagem de encarar a simplicidade fisiológica com a correspondente simplicidade psicológica, ou seja, como escrevia Faria Vasconcellos na sua tentativa de explicar a ideia de Baldwin:

há um desenvolvimento psychologico que se harmonisa com o desenvolvimento physico, a serie d'estas correlações de crescimento, não se pode estabelecer com exactidão senão começando pelas origens, sendo postos em maior evidência os phenomenos internos com os quaes náo é possível estabelecer correspondencias physiologicas (Faria de Vasconcellos, s.d.:42-43).

De qualquer modo, este tipo de abordagem também era tido como relevante para o conhecimento da infância em si. Faria de Vasconcellos continuava a sua explicação, dizendo:

Quanto á própria creança, o methodo genético tem uma importância fundamental, pois observando e experimentando as suas origens mais obscuras, a sua evolução e desenvolvimento physico e mental, as variaçôes e as crises por que ella passa, é que melhor se penetra na physiologia e psychologia da creança (Faria de Vasconcellos, s.d.:43).

A psicologia genética começa a afirmar-se tanto pelo que se pode aproximar às ciências naturais e à ciência médica como pelo que interessa ao evolucionismo. No princípio do século XX, Robert Gaupp também associa a emergência da psicologia da infância às ideias evolucionistas e à aproximação às ciências naturais. Isto comporta duas consequências: empurra cada vez mais o estudo da psicologia para os métodos indutivos das ciências e passa a considerar o estudo da criança tanto em função da necessidade de compreender a especificidade da infância como para compreender o desenvolvimento psíquico do ser humano. É que, para alguns intelectuais, não só o desenvolvimento do indivíduo comportava as fases do desenvolvimento da humanidade como a criança comportava um esboço do desenvolvimento do indivíduo. Esta relação da compreensão da ontogénese associada à filogénese perde vigor nos finais de Oitocentos e ao longo das primeiras décadas do século XX. Já Baldwin se in- 
terrogava sobre essa relação, quando ela supunha um conhecimento sobre a "ontogenia mental" e a psicologia individual que estava longe de existir na época. Faria de Vasconcellos, nos inícios de Novecentos, não se mostra favorável a tal compreensão. Para ele há uma série de variadas influências "mecânicas, esforços ou pressôes exteriores, accidentes, bruscas mutaçóes do meio" que podem alterar as condiçóes fisiológicas do crescimento e até a ordem e o número das fases do desenvolvimento da criança. $\mathrm{O}$ mesmo raciocínio é aplicado ao desenvolvimento mental. Assim, para ele, "na recapitulação da evolução psychica deve haver numerosas e variadas lacunas”. Há toda uma série de fatores externos a considerar como os de natureza intelectual e social, que "tudo isso apressará a maturidade da intelligencia e abreviará as phases do seu desenvolvimento". Também Alberto Pimentel Filho, escrevendo em plenos anos 1920 da centúria de Novecentos, não aceita a lei da recapitulação "porque, posto haja afinidades de carácter e de procedimento entre crianças e os selvagens, por exemplo, nunca uma criança reproduzirá integralmente a fisionomia intelectual e moral do homem primitivo" (Pimentel Filho, 1935:50).

Mas as razóes que justificaram a compreensão do desenvolvimento vão continuar a desafiar várias personalidades marcantes do pensamento psicológico e a pretensa cientificidade não diminuirá as divergências entre as diferentes abordagens. Por outro lado, também não esmorecerá o interesse pelo estudo científico da criança, antes pelo contrário, aqueles aspectos que mais implicavam com o desenvolvimento físico e intelectual vão merecer cada vez mais atenção.

O século XX parecia promissor para quem acreditava no progresso. Por ocasiáo da instauraçáo do regime republicano em Portugal, apoiando-se no saber médico-pedagógico que vinha de décadas anteriores, e sobretudo dos estudos de ciências médicas, da antropologia e da psicologia experimental, alguns médicos e pedagogos portugueses esforçaram-se para que em Portugal singrasse a pedologia como ciência natural da criança, seguindo a proposta de Oscar Chrisman, discipulo do célebre Stanley Hall (Pimentel Filho, 1935). Contudo, havia bem consciência que se estava no início dum processo científico. Escrevendo no início do século XX, Faria Vasconcellos (s.d.:26) era bem claro quanto a isso: 
A pedologia é uma sciencia nova, e desnecessário é dizer que se, precisamente por estar n'um período embryonario de elaboração doutrinal e phenomenica, ainda não póde elevar-se à organisação d'um programma de pedagogia pratica.

Foi, sobretudo, nas primeiras décadas do século vinte que se investiu de forma mais consequente na obtenção dum conhecimento que integrasse a realidade portuguesa. $\mathrm{O}$ estudo scientifico da creança está ainda muito atrazado e seria extremamente imprudente deduzir dos resultados actuaes da psychologia experimental applicaçôes pedagógicas precisas e positivas.

Quase no fim da segunda década de Novecentos, vários estudos sobre a criança portuguesa permitiam a Alves dos Santos publicar dois livros bem significativos do seu esforço neste domínio. Um, publicado em 1917, tinha como título $O$ crescimento da criança portuguesa. Subsidios para a constituiçáo duma pedologia nacional; o outro, intitulado Educação nova. As bases. O corpo da criança (1919), deveria ser seguido de um segundo volume sobre o desenvolvimento mental da criança, o que não veio a acontecer por o autor ter falecido antes de terminar esse trabalho. Ambos os livros ilustram bem quanto o professor da Universidade de Coimbra e responsável pelo Laboratório de Psicologia Experimental da mesma instituição aposta na pedologia como ciência natural da criança. Tal como ele escrevia em Educação nova, a criança podia ser "estudada em si mesma”, sem outro intuito que não fosse "o de a conhecermos, do mesmo modo que o botanista estuda as plantas, ou o entomólogo, os costumes dos animais". Neste caso, o estudo da criança não poderia deixar de “submeter-se às regras do método" (Santos, 1919:14) exigidas em qualquer investigação científica. Embora seja evidente a colagem a um discurso positivista que certamente pretende sublinhar a necessidade do investimento na investigação do desenvolvimento da criança, ele inscrevia-se claramente num movimento pedagógico internacional e num contexto político nacional muito favorável a encarar a educação como condição necessária ao progresso. Deste modo, a generosidade filantrópica e a lógica cientificista que sustentam a emergência da pedologia são bem esteios duma ordem política que é intérprete da modernidade mediada pelo Estado-nação. A pedologia parecia poder contribuir para explicar como se desenvolvia a criança; desse modo, surgia como a ciência que deveria sustentar as orientaçóes capazes de assegurar uma populaçáo mais capacitada a cumprir o projeto de progresso nacional, caro à ideologia republicana. Esse intuito esteve sempre muito presente na açáo de António 
Aurélio da Costa Ferreira (Pereira e Ferreira, 1999). Conhecido o seu empenho, foi chamado a colaborar na formação de professores, onde bem tentou convencer os futuros docentes da conveniência da pedologia. Numa das suas palestras, colocou a referida ciência emergente ao lado de outras disciplinas táo inovadoras na época quanto necessárias àquilo que os pedagogos mais modernos julgavam fundamental generalizar-se nas escolas para que se regenerasse a sociedade portuguesa. Dizia ele:

Bem posso dizer como eu mesmo dizia no último Congresso Pedagógico de Lisboa: "querer e crer que sem conhecimentos de pedologia, de higiene escolar, de metodologia dos trabalhos manuais e da ginástica, possam saír das nossas escolas normais professores dignos da nossa época, a quem os governos possam confiar a educação das novas geraçôes, capazes, como dizia, parece-me, numa das suas célebres liçôes de pedagogia, o meu querido mestre, Dr. Bernardino Machado, capazes não só de transmitir-'em tôda a sua pureza o património da civilização dos antepassados, a hercúlea fôrça atávica que nos pode permitir reabilitar-nos perante a história' - mas tambêm capazes de fazer tudo o que fôr possível fazer-se para fomentar o progresso, melhorar a raça, melhorar o solo, melhorar o país; querer que aqueles a quem compete fazer e refazer a pátria, a façam e refaçam como noutros tempos, como no nosso tempo já não deve fazer-se, é tấo estulto como querer confiar hoje a defeza da nossa terra aos heróis de outrora, a valentes de cota e malha, ou os progressos do nosso comércio, às antigas e gloriosas caravelas!" (Ferreira, 1920:9).

A pedologia surgia a estes republicanos convictos da força transformadora da educação como a ciência emergente que podia sustentar uma ação educativa mais de acordo com a modernidade. Ela justificava-se pela complexidade da compreensão do desenvolvimento infantil e pela necessidade de fundamentar a diversidade das açóes sobre as crianças sujeitas a situaçóes e a problemas muito diferentes. O campo constituía-se a partir de diferentes abordagens e isso levava a que pudesse ser dividido em pedologia pura, quando apenas visava o estudo desinteressado da criança, e em pedologia aplicada, quando o estudo visava determinado fim. A pedologia pura, sendo o "estudo integral da criança", compreendia a biologia infantil, a psicologia infantil e a sociologia infantil; a pedologia aplicada compreendia a pediatria, a pedotecnia judiciária e a pedagogia experimental. Todas essas especialidades tinham ainda subdivi- 
sões, pelo que a pedologia se constituía como ciência totalizante da criança, como domínio do conhecimento que devia organizar a compreensão fundamentada sobre os que se encontravam em desenvolvimento e a orientar todos aqueles que atuavam com estes.

Deve-se acrescentar que a pedologia foi ensinada, em Portugal, no âmbito de cursos de formação de professores, durante as primeiras décadas do século $\mathrm{XX}$, acreditando-se que ela seria fundamental para que os futuros docentes pudessem cuidar de adequar o ensino às capacidades dos seus alunos. A primeira tentativa de ensino oficial da pedologia terá sido feita por Costa Sacadura, na Escola Normal do Calvário, em Lisboa, durante o ano letivo de 1908/09, portanto, quase na véspera da instauração do regime republicano. A segunda deve ter sido realizada no ano letivo seguinte por Faria de Vasconcelos, professor da Universidade Nova de Bruxelas, que realizou na mesma escola umas conferências sobre pedologia e pedagogia experimental, que já tinham sido anteriormente apresentadas na Sociedade de Geografia de Lisboa.

Algumas liçôes desses cursos foram impressas, dando-se a conhecer a públicos mais vastos. Uma delas, apresentada por António Aurélio da Costa Ferreira na Escola Normal de Lisboa, em 1915, foi publicada no jornal da Tutoria da Infância e no Anuário da Casa Pia de Lisboa e, no fim da década, num pequeno livro intitulado Algumas liçôes de psicologia e pedologia. A lição de abertura do curso de pedologia, a que ele deu o título de "O ensino da pedologia na Escola Normal Primária”, dá testemunho da novidade dessa matéria:

A S. Ex. ${ }^{\underline{a}}$ o actual Ministro de Instrução Pública caberá a honra de ter introduzido no quadro dos estudos do curso normal, o ensino regular da pedologia. Por minha parte, procurarei corresponder aos desejos de S. Ex. ․ㅡo Ministro, repartindo com todos os meus alunos o que da matéria souber e com êles estudando o que fôr preciso estudar, pondo ao seu dispôr os meus hábitos, os meus recursos e o meu método de trabalho.

Que a dedicaçáo e a lialdade com que sempre uso servir nos lugares para que me nomeiam, possam compensar outras minhas faltas, que eu possa provar ao digno director e ao ilustre corpo docente dêste estabelecimento de instrução, a que agora muito me honro de pertencer, quanto desejo contribuir para o bom nome e reputação desta Escola, e finalmente que eu possa ter o maior e melhor pago que desejo ter: o poder ouvir dizer aos meus alunos que na vida prática de bastante 
lhes serviu o que procurei ensinar-lhes, os conhecimentos que lhes transmiti, os hábitos que lhes criei e as prelecçôes que lhes fiz" (Ferreira, 1920:15).

António Aurélio da Costa Ferreira era um médico, devotado à causa republicana desde os seus tempos de estudante de Coimbra, que cedo se interessou pelo campo educativo e a ele dedicou boa parte do seu esforço mas que deu especial atenção aos estudos sobre a criança e a abordagens médico-pedagógicas precisamente a partir desta nomeação como professor da Escola Normal de Lisboa (Pereira e Ferreira, 1999). No entanto, Costa Ferreira era também já um político e um educador experimentado, pelo que sabia das reaçôes à novidade e, muito em especial, às questóes mais progressistas em matéria pedagógica. Assim, náo admira que ele se refira, logo na abertura do curso de pedologia, às reaçóes negativas que as liçóes sobre esta temática provocavam e como pensava abordá-las, tendo em atençáo o público a que se destinavam. Dizia ele:

Eu sei com que razão se tem apresentado contra o ensino da pedologia, ou estudo da criança, aos professores de instrução primária, o argumento de que êle tem levado êstes a distrair-se das suas funçóes docentes, para se dedicarem a estudos e experiências que não só prejudicam, porque afastam o professor da sua principal missáo: instruir e educar, como tambêm porque o levam a fornecer dados que por insuficiência ou carência de preparação scientífica, que só em cursos superiores e especiais se pode adquirir, são em regra dados perdidos, cheios de erros, falseados, quási inúteis para a sciência.

Mas o que eu pretendo fazer não é preparar psicólogos, antropologistas, filósofos; nem eu, nem ninguem deveria pretender fazê-los numa escola normal primária, principalmente com as habilitaçôes que os senhores podem e devem ter. O que eu pretendo fazer é ensinar os principais elementos de pedologia, que a sua preparação literária consente e que os professores devem conhecer para melhor ensinar. [...]

Os exercícios que habitualmente passarei, serão exercícios de educação scientífica e neles terei em vista náo só ensinar como se estuda e desenvolve as faculdades da criança, mas tambem o ensinar a estudar e a desenvolver as faculdades dos que a têm de educar (Ferreira, 1920:14-15).

No ano seguinte, tendo continuado com as liçóes do curso de pedologia na referida escola, ele expressou melhor as suas orientações por ocasião da lição 
de encerramento que realizou na sala de Física da Faculdade de Ciências de Lisboa e que fez publicar no Boletim do Ministério da Instrução Pública e no Anuário da Casa Pia de Lisboa, e, mais tarde, também no já mencionado livrinho Algumas liçóes de psicologia e pedologia. Nas suas palavras nota-se uma especial preocupação de dar conhecimentos que possam servir ao bom exercício da docência. Afirmava ele:

Tem sido sempre minha principal preocupaçáo o professar de pedologia que possa directamente aproveitar ao ensino primário, não aconselhando senão processos de observação e experiência, fáceis, compatíveis com a preparação dos alunos da Escola Normal Primária, e que não distraíam [sic] os mestres das obrigaçóes didácticas, e antes pelo contrário contribuam para que melhor as cumpram, fazendo sempre lembrar-lhes que, mais do que ministrar noçóes, lhes compete preparar o espírito dos alunos para as receber, e para isso é indispensável saber conhecer os alunos, saber o que são, conhecer a personalidade de cada um, e saber-lhes aproveitar o feitio. Esta tem sido de facto a preocupação principal e a orientação com que tenho preparado as minhas liçôes e elas claramente se notam nas três liçóes que já publiquei: - O ensino da pedologia, na Escola Normal Primária, O pêso do corpo da criança, e A agudeza visual e a auditiva, debaixo do ponto de vista pedagógico (Ferreira, 1920:92).

Sublinhe-se, entretanto, que Alberto Pimentel Filho, tendo sucedido a António Aurélio da Costa Ferreira como professor de pedologia, publicou em 1929 as suas liçóes de pedologia apresentadas, desde 1922, na Escola Normal de Lisboa e que o livro, intitulado Pedologia (esboço de uma história natural da criança), veio a merecer reedição em 1935, o que testemunha o interesse pelo seu conteúdo e quanto ainda parecia interessante um saber global sobre a compreensão do desenvolvimento da criança.

$\mathrm{Na}$ verdade, a pedologia pretendia singrar como campo de estudo do crescimento da criança. De certo modo, ela emergia sobretudo como a necessidade de especialização capaz de assegurar um conjunto de referências e orientaçôes que se deviam fundar num conhecimento científico e contribuir para que o Estado se fundasse numa populaçáo sadia e suficientemente instruída de acordo com uma pedagogia ativa, tendo em vista preparar o indivíduo para a vida. Para isso, importava conhecer bem a evolução do crescimento, pois que devia ser por ela que se devia orientar a educaçáo a dar às crianças e aos ado- 
lescentes. Todavia, toda esta aposta no estudo científico da criança não parecia suficiente para alterar um modelo de classificação das idades que já encontráramos num médico português, nos inícios de Oitocentos. Se para Alves dos Santos, em livro publicado nos finais da segunda década do século XX, as fases da vida das crianças, definidas a partir do "critério fisiológico da dentição, combinado com o da maturidade sexual", colocavam a adolescência entre os sete e os 12 ou 14 anos (para as raparigas, entre os 11 e os 13) e a puberdade desde o fim da adolescência, até aos 16 anos, para os rapazes, e dos 15 para as raparigas (Santos, 1919), essa periodização da evolução do crescimento assemelha-se muito à da sistematização apresentada por António Ribeiro de Carvalho nos inícios de Oitocentos. De facto, ambas as sistematizaçóes se aproximam ao apresentarem uma sucessão de idades onde a infância terminava aos três anos, seguindo-se-lhe a puerícia e, depois, a adolescência antes da puberdade. A classificação de Alves dos Santos revela maior conhecimento das alteraçóes anatómicas e fisiológicas da criança e apresenta limites cronológicos mais razoáveis para o fim da puerícia e da adolescência, mas reforça a ideia de que o médico oitocentista estava já a romper com antiga classificação das idades e a tentar caminhar em direção a uma que resultasse da experiência e dos métodos da nova medicina. Todavia, não deixa de suscitar estranheza que nas duas classificaçôes se coloque a adolescência como um período anterior à puberdade, o que não condiz nem com as propostas mais antigas nem com a concepçáo atual. Alberto Pimentel percebeu que a designação de adolescência era equívoca e sentiu necessidade de a explicitar. Para isso recorreu a uma citação de Godin, que precisando a significação do termo adolescência escreveu:

A que período da vida da criança convém pois o têrmo adolescência?

Se entendermos dever dar à palavra 'adolescência' o seu sentido original, a saber período de crescimento, de 'adolescere', crescer, e se nos reportarmos apenas ao alongamento da estatura para determinar o momento dêste período, deveríamos lògicamente designar pelo mesmo vocábulo 'adolescência' a extensão inteira da vida da criança sem excluirmos dela o período do nascimento aos cinco anos, e menos ainda a fase êmbrio-fetal ou intrauterina.

O uso está, na espécie, em contradição flagrante com a lógica, e o melhor seria talvez suprimir uma palavra tão completamente desviada do seu sentido real. Mas está admitido que o termo adolescência se aplique à última fase da infância, à fase peri-pubertária, e que seja consagrado especialmente à última impulsão um 
tanto importante de alongamento pelos membros inferiores (Pimentel Filho, 1935:112).

Alves dos Santos também parece ter dúvida quanto à designação de adolescência porque, quando tenta a explicitação deste período, começa por justificar a sua utilização por ser costume associá-la à "fase peri-pubertária" (Santos, 1919:21). Mas onde a evidência de dúvida surge mais eloquente é na parte em que ele trata dos cânones antropométricos da criança. De facto, ao apresentar diversas medidas e algumas conclusóes sobre as características mais específicas para diferentes fases, ele passa da puerícia para a puberdade inserindo aqui duas vezes a expressão adolescência associada a qualidades normalmente associadas ao período iniciado com a puberdade. A ambiguidade da sua posição deriva de ele ter dificuldade em articular discursos diferentes sobre o desenvolvimento da criança. Ao fazer uma leitura mais próxima dos dados antropométricos parece não ter outra solução que estabelecer uma proximidade ambígua entre a adolescência e a puberdade. Assim, não fazia sentido manter uma fase distinta entre a puerícia e a idade pubertária. No seu livro $O$ crescimento da criança portuguesa. Subsidios para a constituição duma pedologia nacional, logo após a apresentação dos quadros com os dados antropométricos da puberdade (que diz ser por volta dos 15 anos), discorre sobre este período de modo que, umas vezes, a adolescência parece ser uma fase preparatória da puberdade mas, em outras, também deixa a ideia de que são designaçôes para um mesmo período de desenvolvimento. Vejamos como ele dá sequência aos dados sobre a puberdade:

A adolescência constitue uma época de instabilidade orgânica, que prepara a criança para os desequilíbrios da puberdade.

"Nenhum período da vida, escreve Mendousse, é mais fecundo em surpresas de todo o género, porque, ao lado das faculdades novas que começam a desenhar-se, persistem os hábitos antigos, que não querem desaparecer".

Daqui, um conflito de energias, que lança o adolescente em perplexidades, cuja eficiência, por vezes, lhe pode ser funesta.

Stanley Hall redigiu o catálogo dos contrastes e das flutuaçôes mentais e morais da adolescência, pelo qual se vê que, de facto, a criança desta idade possue uma vida inadaptada, que é fonte dos seus érros e da maior parte dos seus sofrimentos (Santos, 1917:105). 
Da forma como articula o discurso, embora num primeiro momento pareça dizer que a puberdade é consequência da instabilidade da adolescência, transparece a ideia que está a manter uma indefinição, chamando a legitimar a sua posição autores que claramente se debruçaram sobre a adolescência. Se dúvidas houvesse sobre essa ambiguidade elas são suscetíveis de serem clarificadas quase ao terminar a abordagem dos cânones antropométricos da puberdade, ao escrever referindo-se exatamente a este período, que a "puberdade é o centro do crescimento; a idade crítica, por excelência; aquela, em que se decide a sorte, todo o futuro da criança", mas que remete logo para uma transcrição de Comparé, colocada no fim da página cuja tradução nos diz que a "adolescência é a idade da puberdade, a idade onde a sexualidade se estabelece definitivamente" (Santos, 1917:106).

Chegado aqui, Alves dos Santos parece estar bem sintonizado com um sentimento generalizado da sociedade e até com o da psicologia do tempo. Stanley Hall que, no início do século XX, publicou The adolescence, deixou bem evidente que esta fase de crescimento era problemática, marcada pela contradição, sendo uma idade onde as potencialidades genéticas se confrontavam com as exigências da vida social. Todavia, tanto Alves dos Santos como Alberto Pimentel testemunhavam a dificuldade em fixar a adolescência no período cronológico associado ao início da puberdade. Preocupados com o estudo científico da criança, querem a correspondência da designação ao significado da mesma. Estando especialmente condicionados por estudos antropométricos e pela dimensão fisiológica, parece-lhes mais adequado atribuir a designação de adolescência ao período em que o corpo mais crescia e se modificava. Mas era evidente que a compreensão de adolescência já não podia conter-se numa estrita perspectiva fisiológica. A sociedade precisava de definiçáo de períodos que traduzissem outras capacidades do indivíduo e possibilitassem fixar responsabilidades em função das condiçóes materiais e tecnológicas que sustentavam o processo civilizatório. Faria Vasconcellos parece ter compreendido que ainda se estava numa fase bastante incipiente da problemática e trata da puberdade como coincidindo com a adolescência. Mas é claro para ele que se está num período de crise não só de um ponto de vista físico, mas também mental. Nas suas palavras, a puberdade era "um período de transformação e de crise”, que os psicólogos e os pedagogos ainda conheciam mal. Só Stanley Hall, no seu interessante livro The adolescence, havia considerado os mais "diversos 
aspectos physicos, psychicos e sociaes", na busca de esclarecer os problemas desta "época importantíssima do ser humano" (Faria Vasconcellos, s.d.:103, 104). Ou seja, a ambiguidade dos conceitos era o resultado de ainda se estar diante de uma modernidade pouco conseguida, de uma modernidade que era mais vontade que realidade efetiva. Esta situação é apenas um exemplo de que o desejo anda frequentemente muito à frente da capacidade de concretizaçáo e que a modernidade é um processo que náo surgiu de mero enunciado ideológico. Por muito que alguns republicanos gostassem de ver a ciência a fundamentar todas as decisóes educativas e a esclarecer as opçóes a seguir, não se possuía ainda um conhecimento suficientemente sólido que sustentasse a vontade de dar à educação um cariz eminentemente científico. A própria ciência emergente em que se devia fundar não vingou. Nem sempre os caminhos da modernidade são óbvios.

\section{Referências}

BECCHI, Egle; JULIA, Dominique (Org.). Histoire de l'enfance en Occident. du XVIII siècle à nos jours. Paris: Seuil, 1998. v. II.

BECQUEREL, A. Traité elementaire d'hygiene privée et publique. 3. ed. Paris: P. Asselin, 1864.

CAMÓES, Luís de. Poesia completa. Editora Nova Aguilar, 1988.

FARIA DE VASCONCELLOS. Liçôes de pedologia e pedagogia experimental. Lisboa: Antiga casa Bertrand, José Bastos \& Cá. Editores, s.d.

FERREIRA, António Aurélio da Costa. Algumas liçôes de psicologia e pedologia. Porto: Typ. Costa Carregal, 1920.

FERREIRA, António Gomes. A criança e o seu desenvolvimento em discursos médicos e pedagógicos que circularam no contexto português (séculos XVIII a XX). Educação em Revista, Belo Horizonte, v. 26, n. 1, p. 215-234, 2000.

. A criança no conhecimento médico de seiscentos. Revista Portuguesa de Pedagogia, ano XXIII, p. 401-424, 1989.

. Gerar, criar, educar: a criança no Portugal do Antigo Regime. Coimbra: Quarteto Editora, 2000.

- A difusão da escola e a afirmação da sociedade burguesa. Revista Brasileira de História da Educação, Campinas, n. 9, p. 177-198, jan./jun. 2005.

GAUPP, Robert. Psicologia del niño. Barcelona/Buenos Aires: Editorial Labor, 1927.

GIDDENS, Anthony. As consequências da modernidade. Oeiras: Celta, 1995. 
GONDRA, José G. Artes de civilizar: medicina, higiene e educação escolar na Corte Imperial. Rio de Janeiro: Eduerj, 2004.

GOUVÊA, Maria C.S. Tempos de aprender - a produção histórica da idade escolar. Revista Brasileira de História da Educação, Campinas, n. 8, p. 265-288, jul./dez. 2004.

LUC, Jean-Noël. Les premières écoles enfantines et l'invention du jeune enfant. In: BECCHI, Egle; JULIA, Dominique (Org.). Histoire de l'enfance en Occident: du XVIII siècle à nos jours. Paris: Seuil, 1998. v. II.

MARTINS, Álvaro. A higiene e a educação psíquicas nos três primeiros anos de vida. Porto: Papelaria e Typographia Academica, 1898.

MOULY, G.J. Psicologia educacional. São Paulo: Pioneira, 1979.

MUSSEN, P.H.; CONGER, J.J.; KAGAN, J. Desenvolvimento e personalidade da criança. 4. ed. São Paulo: Harper \& Row do Brasil Ltda., 1977.

MUSSEN, P.H. O desenvolvimento psicológico da criança. Rio de Janeiro: Guanabara, 1979.

PARRA, Francisco Ignacio. Algumas palavras sobre os efeitos, tratamento e meio de prevenir o esfalfamento mental. Porto: Papelaria e Typographia Morgado, 1898.

PEREIRA, José Augusto; FERREIRA, António Gomes. António Aurélio da Costa Ferreira. Um educador na Primeira República. Lisboa: Casa Pia de Lisboa, 1999.

PIMENTEL FILHO, Alberto. Pedologia (esboço de uma história natural da criança). 2. ed. Lisboa: Livraria Editora Guimarães \& C ${ }^{a} ., 1935.2$ v.

ROSA, M. Psicologia evolutiva. Petrópolis: Vozes, 1986.

ROUSSEAU, Jean-Jacques. Emílio. Lisboa: Publicaçôes Europa-América, 1990.

SANTOS, Alves. Educação Nova. As bases. O corpo da criança. Lisboa: Livrarias Aillaud e Bertrand, 1919.

SANTOS, Alves. O crescimento da criança portuguesa: subsídios para a constituição duma pedologia nacional. Coimbra: Imprensa da Universidade, 1917.

SARMENTO, Aurélia de Moraes. Hygiene da primeira infância. Porto: Imprensa Portugueza, 1891.

SAWREY, J.M.; Telford, C.W. Psicologia educacional. Rio de Janeiro: Ao Livro Técnico S.A., 1971.

TRAN-THONG. Estádios e conceito de estádio de desenvolvimento da criança na psicologia contemporânea. Porto: Ediçóes Afrontamento, 1983. 2 v. 